\title{
DYNAMIC ANALYSIS OF BOGIE WHEELSET- A REVIEW
}

\author{
Patrick Emanuel Urassa \\ Addis Ababa University, Addis Ababa Institute of Technology, \\ African Railway Centre of Excellence, Rolling stock Department. \\ Addis Ababa, Ethiopia
}

\begin{abstract}
The dynamic of railway vehicle wheelsets is influenced by the actions of the conicity of the wheels and the creep forces acting between the wheels and rails. In this review paper, the dynamics analysis of wheelset has investigated, equations of motion have formulated and stability criteria obtained which indicate the effects of varying the various parameters of the system. The nature of the motion at the critical speed is investigated and the mode of energy conversion between the forward motion of the vehicle and the lateral motion of the wheelset is explained. From a dynamic analysis, it is shown how the critical speed of the wheelset slips and suspension stiffness relates to the kinematic motion.
\end{abstract}

Keywords - Dynamic analysis, Wheelset, Kinematic Oscillation, Self-steering, wheel/rail contact point

\section{WHEELSET DYNAMICS}

\section{A. 1.1 Introduction}

The wheelset is the combination of two wheels and single axle attached together in the bogie assembly of a railway vehicle. They are attached at the frame assembly beneath each end of a carbody. The two wheels are rigidly connected by an axle thus called wheelset, the pair of rails which provide two contacts points with two wheels from wheelset are also considered to be rigid. The wheelset and pair of rails two contact point are one in each rail. The wheel has conical profile which is one of the oldest and most important inventions in railway engineering, it provides effective guidance of the vehicle on a curved track by varying rolling radii of the wheels(True, 1993). Most North American freight railway have two bogies with two or three wheelsets, depending on the type of vehicle. The short freight railway vehicle generally have no bogies but instead have two wheelsets.

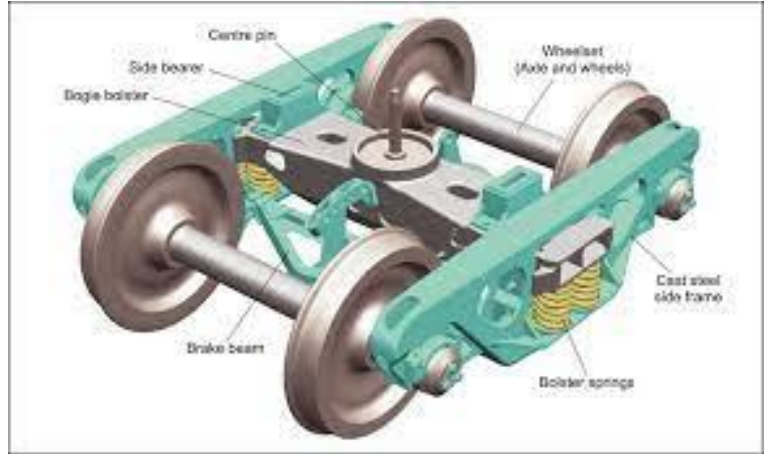

Figure 1: Bogie assembly with two wheelsets

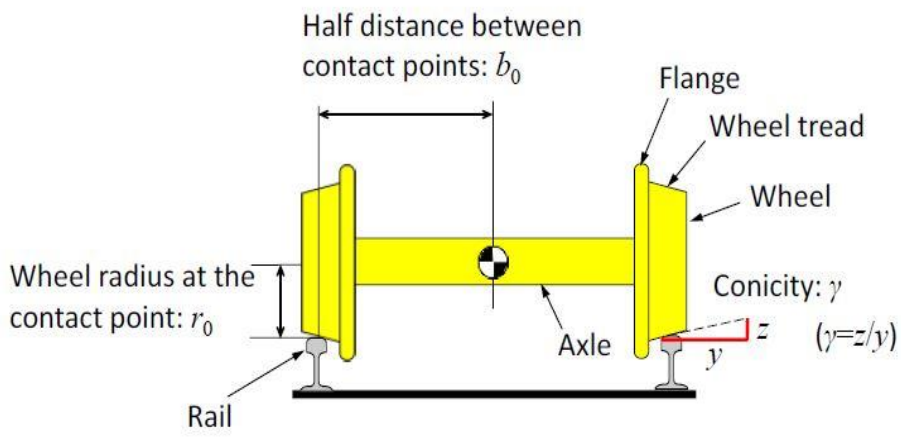

Figure 2: wheelset with parts nomenclature

\section{B. 1.2 Problem of statement}

The conical profile (conicity) of the wheels as most important inventions in railway engineering, however, it has a serious side-effect, which is called kinematic oscillation. This oscillation is a swaying motion of a rail vehicle caused by the conicity of the wheel. It rises from the interaction between adhesion forces and inertial forces. At low speed, the force between wheels and rails at the contact point (adhesion) dominates but, as the speed increases, the forces between wheels and rails and inertial forces become comparable in magnitude and gradually the oscillation (hunting motion) begins at a critical speed. Above this critical speed, the motion can be violent, damaging track and wheels and potentially causing derailment. 


\section{1.3 Objectives of this review paper}

\section{1) 1.3.1 Main objective}

The main objective of this paper is to review studies related to dynamic analysis of bogie wheelset

\section{2) 1.3.2 Specific objectives}

- To review different types of papers available to effectively ascertain bogie wheelset dynamic analysis

- To comparing and analyzing the strength and weakness of previous studies related to bogie wheelset dynamic analysis

- To identify the research gap

\section{1.4 Significance of this review paper}

The paper shows the merits and demerits associated with conicity, therefore to have coning profile in the wheel is inevitable and to counteract the problem caused by it there are some recommendations to consider. For example, large conicity is advantageous to pass sharp curves smoothly, but result to less hunting stability. To satisfy both of curving performance and running stability it's recommended to use the wheels with conicity of $1 / 20$ or $1 / 40$.

\section{LITERATURE REVIEW}

\section{A. 2.1 Introduction}

Literature review gives comprehensive overview about previous research work done in bogie wheelset dynamics analysis, start with systematically searching for papers that focus on wheelset dynamics. Database search was conducted on well-known databases science direct, researchgate, Francis \& Tylor, google scholar and Scopus. Keywords such as 'wheelset' 'dynamics' were searched in title. The focus was based in English academic papers and journal papers as well as conference proceedings that published recently. In the first step, term 'wheelset' then 'dynamics' were searched for, then in second step, manually checked titles was done. The third step, the related papers were searched following a forward snowball effect, by exploring citations and references of selected papers. Final step, a final refinement was made and sorting out all papers.

\section{B. 2.2.1 Hunting oscillation}

A hunting oscillation is a swaying motion of a railway caused by the coning action or conicity of which the directional stability of forces between wheel and rails depends. It can be caused by the interaction of adhesion forces and inertial forces. At low speed, the forces between wheels and rail dominates but, as the speed increases, the forces between rail and wheels and inertial forces become comparable in magnitude and the oscillation begins at a critical speed (Wickens, 1996),(Soleimani \& Moavenian, 2017) At moderately high speed, the motion can be violent, damaging track and wheels and potentially causing derailment. This problem is because the wheels rotate at the same angular velocity, if the wheels would have differential unit the problem would have not occur. The abilities of curving and hunting stability usually require opposing properties on the bogie components. For example, large conicity is advantageous to pass sharp curves smoothly, but result to less hunting stability. To satisfy both of curving performance and running stability it's recommended to use the wheels with conicity of $1 / 20$ or $1 / 40$.(Taylor, 2009)

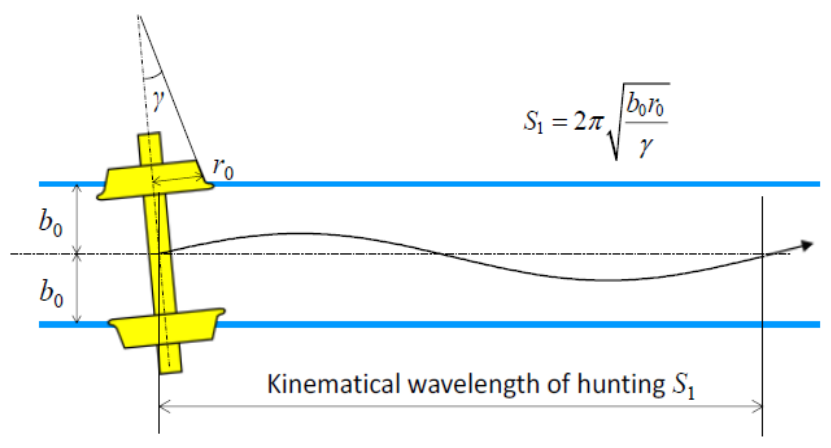

Figure 3: Wheelset hunting motion

George Stephenson explained kinematic oscillation as wheelset dynamics, which resulted into vibration. This vibration is superposed on the steady rolling of the wheelset and represents a 3D motion, which is usually described by lateral displacement and yaw. The first analytical study was carried out by Klingel. Several extensions of Klingel's theory appeared later partly related to the non-conical wheel profiles, partly related to wear.(Antali et al., 2015)

Also, Iwnicki stated that, this kinematic oscillation is modified by the effects of creep. When combined with creep, the resulting oscillation is called hunting. Carter. FW derived the equations including creep, from which the critical speed can be determined above which steady rolling is unstable to hunting.(Carter \& A, 1926)

\section{2.2.3 Self-steering ability}

The self-steering ability (self-centering) is the function to return automatically to the center of the track when a wheelset moves to one side of the track after passing through the curve without using intentional steering manipulation. Railway vehicles they do not have steering wheels like that of automobiles hence the self-steering ability is produced by the difference of the radii of both side wheels in a wheelset. When a wheelset passing through the curve section, the wheelset moves to the outer side of the curve and the wheel on the outer rail contacts with the rail head in larger radius. Since both wheels are attached to a single axle hence, they will rotate with the same angular velocity, the outer side wheel runs faster than the other wheel, and thus the wheelset can pass the curve smoothly(Goodwin, 1987)(Soleimani \& Moavenian, 2017). When a wheelset is running on straight track, the wheelset is displaced to one side of the track, the wheel of the 
displaced side contacts with the rail head in larger radius and the wheel runs faster than the other one, and the wheelset returns to the center of the track. It should be known that the flanges has nothing to do with wheels passing through the curves or return back to the center of the track but rather the flanges are necessary in case such as passing sharper curves or prevent derailment caused by extraordinary lateral force.(Meijaard, 2016) According to the self-steering ability, if pure rolling is maintained, a wheelset can move back toward the center of the track when it displaces slightly to one side of the track. However, during the regaining motion, the wheelset might go beyond the center and this causes oscillatory motion called kinematic hunting.
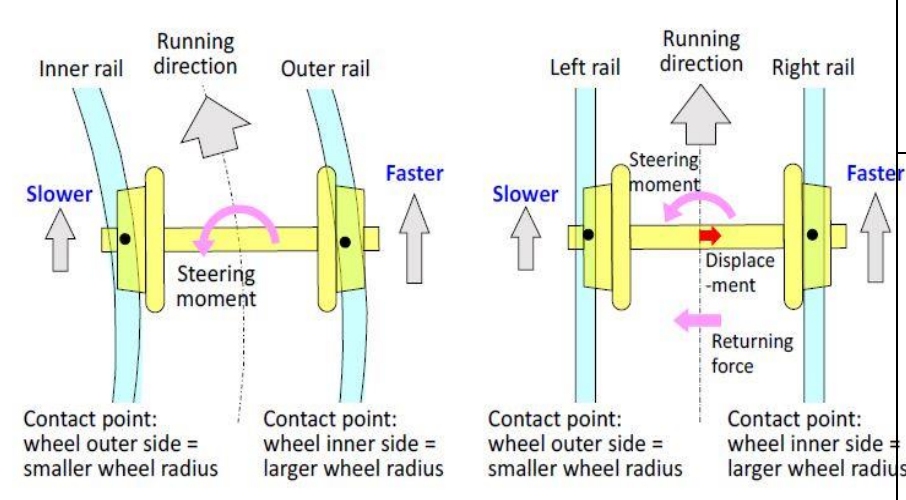

Figure 4: wheelset at curve and at straight track

\section{RESULT AND DisCUSSION}

\section{A. 3.1 Introduction}

Most of dynamics of wheelset used in railway vehicles is influenced by using wheelsets with conical wheels. As we know, the wheelset is a set of a pair of two wheels and an axle; the wheels are tightly pressed into a common axle, so the right and left wheels rotate with a common angular velocity. In wheelset each wheel's tread has a slant such that the radius of the wheel becomes smaller to the outer side of the axle.(Knudsen et al., 1994) This slant is called conicity or wheel tread gradient. Most wheels conicity is, either $1 / 20$ or 1/40. Due to the influence of the conicity of the wheels, speed, creep forces, contact points, flange force and spring stiffness there are some characteristic dynamics resulted, from literature review the following table below compare the work of those researchers in wheelset dynamics analysis

Table 1: Comparison of previous work done on wheelset dynamics

\begin{tabular}{|c|c|c|c|}
\hline Author & Objectives & Strength & Weakness \\
\hline $\begin{array}{c}\text { S, Iwnicki (Simon } \\
\text { Iwnicki, 2003) }\end{array}$ & $\begin{array}{c}\text { Modify the } \\
\text { kinematic } \\
\text { oscillation }\end{array}$ & $\begin{array}{c}\text { Shows } \\
\text { how creep } \\
\text { forces and }\end{array}$ & $\begin{array}{c}\text { No } \\
\text { relationship } \\
\text { between }\end{array}$ \\
\hline
\end{tabular}

\begin{tabular}{|c|c|c|c|}
\hline & $\begin{array}{l}\text { by effects } \\
\text { of creep } \\
\text { forces }\end{array}$ & $\begin{array}{l}\text { hunting } \\
\text { motion } \\
\text { related. }\end{array}$ & $\begin{array}{c}\text { contact } \\
\text { patch and } \\
\text { conicity }\end{array}$ \\
\hline $\begin{array}{l}\text { Carter FW(Carter } \\
\text { \& A, 1926) }\end{array}$ & $\begin{array}{l}\text { Determine } \\
\text { the critical } \\
\text { speed } \\
\text { through } \\
\text { creep forces }\end{array}$ & $\begin{array}{l}\text { Explain } \\
\text { hunting } \\
\text { starts after } \\
\text { attain } \\
\text { critical } \\
\text { speed }\end{array}$ & $\begin{array}{c}\text { No } \\
\text { relationship } \\
\text { between } \\
\text { contact } \\
\text { patch and } \\
\text { conicity }\end{array}$ \\
\hline $\begin{array}{c}\text { M Antali(Antali et } \\
\text { al., 2015) }\end{array}$ & $\begin{array}{l}\text { Determine } \\
\text { the effect of } \\
\text { conicity in } \\
\text { wheel } \\
\text { profile }\end{array}$ & $\begin{array}{l}\text { Show the } \\
\text { merits of } \\
\text { conicity in } \\
\text { the } \\
\text { contact } \\
\text { point and } \\
\text { rolling } \\
\text { resistance }\end{array}$ & $\begin{array}{l}\text { Does not } \\
\text { explain } \\
\text { contact } \\
\text { points in } \\
\text { details and } \\
\text { it affects } \\
\text { dynamics of } \\
\text { wheelset. }\end{array}$ \\
\hline $\begin{array}{l}\text { Knudsen(Knudsen } \\
\text { et al., 1994) }\end{array}$ & $\begin{array}{l}\text { investigate } \\
\text { the effect of } \\
\text { speed and } \\
\text { suspension } \\
\text { and flange } \\
\text { stiffnesses } \\
\text { on the } \\
\text { wheelset } \\
\text { dynamics }\end{array}$ & $\begin{array}{l}\text { Explain } \\
\text { the } \\
\text { function } \\
\text { of speed, } \\
\text { spring } \\
\text { stiffness, } \\
\text { and flange } \\
\text { forces in } \\
\text { wheelset } \\
\text { dynamics }\end{array}$ & $\begin{array}{l}\text { Focuses } \\
\text { only on } \\
\text { behavior in } \\
\text { low velocity } \\
\text { mode }\end{array}$ \\
\hline
\end{tabular}

B. 3.2 Research gap

From reviewing the literature, we have seen about kinematic oscillation (hunting motion) that caused by conicity of the wheels profile as explained by different researchers, and how it affects the performance of train. None of the researcher explaining about relationship between coning profile and contact points. The presence of conicity in the railway wheel reduce the contact area between rail and the wheels hence reduce the rolling resistance and eventually increase running performance.

\section{3.2.1 Contact points}

The high energy efficiency of railway transportation is made possible by the favorably low losses in the rolling contact between the hard surfaces of the wheel and rail, which meet only in a very small contact patch(Lewis, R., Olofsson, 2009). This small contact patch is also contributed by coning wheel profile, as the result of small contact patch the rolling resistance is reduced hence the railway running performance is increased.

\section{3.3 Recommendation for the future aspect}

A railway wheelset, is one of the crucial parts that support the safe operation of railway vehicles. Wheels support the entire weight of cars; however, they cannot be designed as a fail-safe structure where a backup system by other parts can be applied in case of a serious problem. Therefore, absolutely high 
reliability railway wheelset material is demanded in terms of strength, wear resistance, thermal crack and noise and vibration characteristics. Also, for better wheelset dynamic performance, the conicity of the wheel profile is recommended $1 / 20$ or $1 / 40$ according to UIC.

\section{E. 3.4 Conclusion}

The demand for the ride comfort of passengers is getting higher and higher each day, in addition, as the increase of vehicle speed and maintaining good ride quality demanding soar higher day by day, thus bogie system dynamics has to be taken into consideration. Bogie system comprises of wheelset and suspension system which are directly involved in vehicle good ride quality. So, when we are talking about wheelset dynamics, suspension systems are not to be left behind. Consider lateral vibration of a high-speed vehicle is mainly caused by long wavelength track irregularity which cause poor ride quality and its impacts is transferred to the vehicle body by wheelset, since the wheels are direct in contact with the track. To counteract such kind of problem, control techniques are to be applied in the suspension system of railway vehicles through application of variable damper in lateral connection between bogie and car body. The variable damper can change its damping coefficient electrically. This system is called semi-active suspension system since no active force is applied. The main reason to introduce semi-active system is to reduce lateral vibration in lateral direction which cause poor ride quality. The active suspension system uses hydraulic, pneumatic or electric actuators to apply control force(S. Iwnicki, 2009).

\section{REFERENCES}

Antali, M., Stepan, G., \& Hogan, S. J. (2015). Kinematic oscillations of railway wheelsets. Multibody System Dynamics, 34(3), 259-274. https://doi.org/10.1007/s11044-014-9424-9

Carter, F. W., \& A, P. R. S. L. (1926). On the action of a locomotive driving wheel. Proceedings of the Royal Society of London. Series A, Containing Papers of a Mathematical and Physical Character, 112(760), 151157. https://doi.org/10.1098/rspa.1926.0100

Goodwin, M. J. (1987). Dynamics of railway vehicle systems. Journal of Mechanical Working Technology, 14(2), 245-247. https://doi.org/10.1016/0378-3804(87)90070-2

Iwnicki, S. (2009). Future trends in railway engineering. Proceedings of the Institution of Mechanical Engineers, Part C: Journal of Mechanical Engineering Science, 223(12), 2743-2750. https://doi.org/10.1243/09544062JMES1545

Iwnicki, Simon. (2003). Simulation of wheel - rail contact forces. August, 887-900.

Knudsen, C., Slivsgaard, E., Rose, M., True, H., \& Feldberg, R. (1994). Dynamics of a model of a railway wheelset. Nonlinear Dynamics, 6(2), 215-236. https://doi.org/10.1007/BF00044986
Lewis, R., Olofsson, U. (2009). Wheel-rail interface handbook Edited by.

Meijaard, J. P. (2016). The Motion of a Railway Wheelset on a Track or on a Roller Rig. Procedia IUTAM, 19, 274281. https://doi.org/10.1016/j.piutam.2016.03.034

Soleimani, H., \& Moavenian, M. (2017). Tribological Aspects of Wheel-Rail Contact: A Review of Wear Mechanisms and Effective Factors on Rolling Contact Fatigue. Urban Rail Transit, 3(4), 227-237. https://doi.org/10.1007/s40864-017-0072-2

Taylor, P. (2009). Vehicle System Dynamics : International Journal of Vehicle Mechanics and Nonlinear dynamic behaviour of a railway wheelset. April 2013, 37-41.

True, H. (1993). Dynamics of a rolling wheelset. Applied Mechanics Reviews, 46(7), 438-445. https://doi.org/10.1115/1.3120372

Wickens, A. H. (1996). Static and dynamic instabilities of bogie railway vehicles with linkage steered wheelsets. Vehicle System Dynamics, 26(1), 1-16. https://doi.org/10.1080/00423119608969299 